\title{
THE USE OF EEG BIOFEEDBACK WITHIN THE FRAMEWORK OF ASSISTIVE TECHNOLOGIES
}

\author{
Miroslav Musalek
}
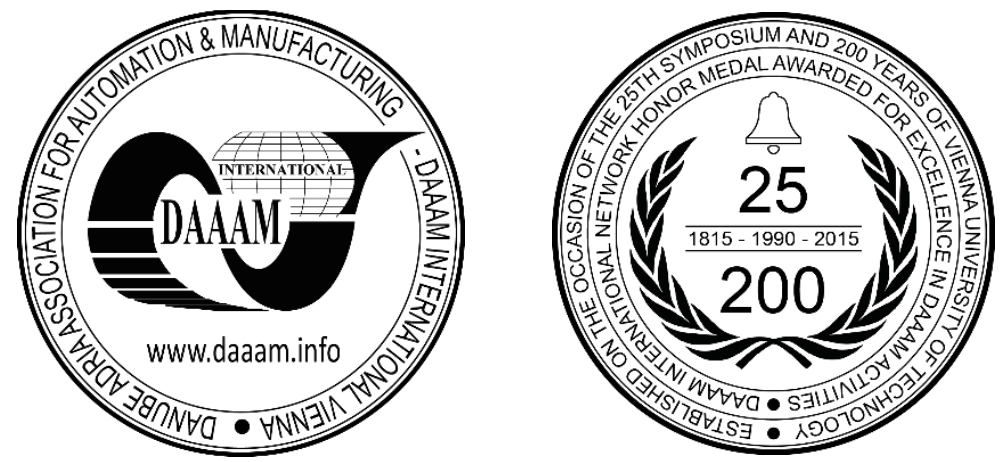

This Publication has to be referred as: Musalek, M[iroslav] (2018). The Use of EEG Biofeedback within the Framework of Assistive Technologies, Proceedings of the 29th DAAAM International Symposium, pp.0817-0821, B. Katalinic (Ed.), Published by DAAAM International, ISBN 978-3-902734-20-4, ISSN 1726-9679, Vienna, Austria DOI: $10.2507 / 29$ th.daaam.proceedings. 118

\begin{abstract}
In today's technological age, which is rapidly evolving, information and communication technologies are commonly used. These technologies are used in the field of assistive technologies that allow living a more dignified life. With the present busy lifestyle, the number of children with learning disabilities is increasing. In order to explore, this issue has selected the method of EEG Biofeedback. The article deals with the possibilities and effectiveness of EEG Biofeedback as assistive technology for the purposes of the alleviation of disorders of learning. In this article, the pre-research was performed which is described and evaluated.
\end{abstract}

Keywords: EEG biofeedback; assistive technology; learning disabilities; therapy

\section{Introduction}

In recent years, new opportunities arise for the use of assistive technology (AT). Assistive technology helps people who have difficulty speaking, typing, writing, remembering, pointing, seeing, hearing, learning, walking, and many other things. Different disabilities require different assistive technologies [1].

Another possible AT definition can be found in [2]. The last few years is increasing the numbers of children, having impaired concentration or learning. In the framework of an extensive set of the AT has been selected for the purposes of this pre-research method EEG neurofeedback. The natural biofeedback, biofeedback, there are literally always. Life itself is the bearer of effective feedback and homeostasis (self-maintenance balance of the organism).

Biofeedback is, therefore, a natural phenomenon but can also be induced for learning, training, treatment. EEGbiofeedback is a method that allows you to regulate the frequency of brain electrical activity ("brain waves"). It is the self-determination of the brain through so-called biological feedback. When the brain receives immediate, targeted, and accurate information about the tuning of its brain waves, it can learn to bring them into line with these brain waves.

Its effect equals the effect of strong psychostimulant without the negative effect. Unlike the psychostimulants it is but its effect lasting because it is about learning - what is the brain in training will learn, you cannot unlearn [3]. The description of this method is described in [4] 
There is also an interesting experience:

"In my 38 years of practice, I have never seen any treatment that comes close to producing the results that Neurofeedback offers...I have seen results achieved in days and weeks that previously took months and years to achieve, using the best methods available to us."

- Jack Woodward, M.D. (Board Certified Psychiatrist)

The paper [5] shows the use of EEG biofeedback for attention deficit disorder and learning disabilities which he shows the positive effect for this chosen purpose. The article [6] focuses on the effect of EEG biofeedback on reading and memory problems. The results of these investigations showed improvement but took into account a small group of test subjects. The article [7] describes the whole process in theoretical and methodical terms, and simultaneously it poses the positive possibilities of EEG neurofeedback for therapeutic purposes. Research [8] can bring new opportunities in this area, especially in combination with both methods.

The aim of this pre-research is to verify the efficacy and the possibility of using the EEG biofeedback as a method of remedying the learning disabilities of children. To this end, research questions were developed to verify the effectiveness of this method. The main question was whether EEG biofeedback therapy could positively affect these disorders. At the same time, it was a question of what features would best be improved.

\section{Material and methods}

\subsection{Learning disabilities}

Learning disabilities are neurologically-based processing problems. These problems can interfere from learning basic things like reading and writing up to a higher level such as orientation, short-term memory and attention.

There is inconsistent terminology in this area, but one of the definitions for illustration [9]:

"Learning disabilities is a general term that refers to a heterogeneous group of disorders manifested by significant difficulties in the acquisition and use of listening, speaking, reading, writing, reasoning, or mathematical skills.

These disorders are intrinsic to the individual, presumed to be due to central nervous system dysfunction, and may occur across the life span. Problems in self-regulatory behaviors, social perception, and social interaction may exist with learning disabilities but do not, by themselves, constitute a learning disability. “

Between learning disorders include [10]:

- Auditory Processing Disorder (APD)

- Dyscalculia

- Dysgraphia

- Dyslexia

- Language Processing Disorder

- Non-Verbal Learning Disabilities

- Visual Perceptual/Visual Motor Deficit

Related Disorders [10]:

- ADHD

- Dyspraxia

- Executive Functioning

- Memory

\subsection{EEG Biofeedback}

The method is based on the principle of biological feedback, i.e. the biofeedback. This consists in the provision of accurate and immediate information to the client for the purpose of learning. There are several types of biofeedbacks, namely biofeedback-providing feedback on body temperature, muscle tension (myofeedback), heart rate, respiratory frequency, skin resistance etc. [11].

In the case of EEG biofeedback (neurofeedback) is provided by the information about the attunement to the user's brain waves. The aim is to teach users to control their brain waves and bring them into mutual harmony. In therapy, this leads to the self-learning of the brain through the control of their own brain waves. The whole process is illustrated in the Fig. 1. 


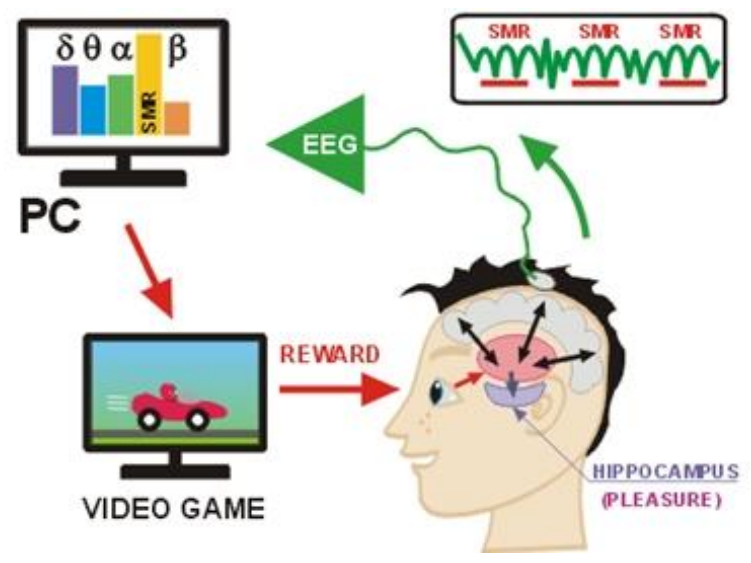

Fig. 1. Diagram of Biofeedback Function [12]

In each session, the user learns to identify, create and maintain the desired brain waves. The user should train until the process is fully automated. Our brain receives a lot of stimulus and therefore chooses information according to severity. The difference between sleep mode and active thinking can be measured using EEG. Due to different situations, the brain works at different frequencies. This division is shown in Table 1.

\begin{tabular}{|c|c|c|}
\hline The name of the wave & Frequency & Description of the status \\
\hline Delta & $0-4 \mathrm{~Hz}$ & slow waves, deep sleep, inability to think \\
\hline Theta & $4-8 \mathrm{~Hz}$ & emotional excitement, inattention \\
\hline Alpha & $8-12 \mathrm{~Hz}$ & in relaxation and rest, anxiety symptoms \\
\hline SMR & $12-15 \mathrm{~Hz}$ & relaxed attention \\
\hline Beta 1 & $15-20 \mathrm{~Hz}$ & focused attention, alert status \\
\hline Beta 2 & $20-30 \mathrm{~Hz}$ & tension, irritability, anxiety \\
\hline Gamma & $>30 \mathrm{~Hz}$ & information processing, learning issues, anxiety \\
\hline
\end{tabular}

Table 1. Frequency zones of brain activity [13]; [14]

\section{Results and discussions}

The methodology is described here for using our pre-research that took place on 2 children of school age. Due to the new GDRP legislation, only the necessary information is provided. 20 sessions with biofeedback were conducted.

\begin{tabular}{|c|c|c|c|c|c|c|}
\hline \multicolumn{7}{|c|}{ User 1 } \\
\hline \multirow{2}{*}{ Hemisphere } & $\begin{array}{c}\text { The name of } \\
\text { the wave }\end{array}$ & $\begin{array}{c}\mathbf{1} \\
\text { session }\end{array}$ & $\begin{array}{c}\mathbf{5 .} \\
\text { session }\end{array}$ & $\begin{array}{c}\mathbf{1 0 .} \\
\text { session }\end{array}$ & $\begin{array}{c}\mathbf{1 5 .} \\
\text { session }\end{array}$ & $\begin{array}{c}\mathbf{2 0 .} \\
\text { session }\end{array}$ \\
\hline \multirow{4}{*}{ Left C3 } & Delta & 28,1 & 28,1 & 28,4 & 26,4 & 26,2 \\
\cline { 2 - 7 } & Theta & 28,8 & 29,8 & 28,5 & 25,2 & 24,6 \\
\cline { 2 - 7 } & Alpha & 16,5 & 15,7 & 17,5 & 18,2 & 17,1 \\
\cline { 2 - 7 } & SMR & 8,46 & 8,77 & 9,6 & 8,35 & 8,1 \\
\cline { 2 - 7 } & Beta 1 & 6,45 & 6,82 & 6,78 & 6,54 & 6,6 \\
\cline { 2 - 7 } & Beta 2 & 7,44 & 6,92 & 8,86 & 7,94 & 7,53 \\
\hline \multirow{4}{*}{ Total } & & $\mathbf{4 , 4 5}$ & $\mathbf{4 , 3 5}$ & $\mathbf{4 , 1 1}$ & $\mathbf{3 , 9}$ & $\mathbf{3 , 5 5}$ \\
\hline \multirow{4}{*}{ Right C4 } & Delta & 27,9 & 29,2 & 29,9 & 28,3 & 30 \\
\cline { 2 - 7 } & Theta & 27,9 & 29,1 & 28,8 & 28,6 & 27,5 \\
\cline { 2 - 7 } & Alpha & 18,3 & 18,2 & 16,8 & 17,6 & 20,5 \\
\cline { 2 - 7 } & SMR & 8,92 & 9,65 & 9,84 & 9,96 & 10,2 \\
\cline { 2 - 7 } & Beta 1 & 6,36 & 6,58 & 6,75 & 6,93 & 7,52 \\
\cline { 2 - 7 } & Beta 2 & 7,61 & 7,25 & 7,62 & 7,94 & 9,63 \\
\hline Total & & $\mathbf{3 , 1 6}$ & $\mathbf{3 , 0 2}$ & $\mathbf{2 , 9 4}$ & $\mathbf{2 , 8 3}$ & $\mathbf{2 , 6 4}$ \\
\hline
\end{tabular}

Table 2. Therapeutic measurement of the user 1 with EEG biofeedback 
For the data processing, the qualitative method of examination was supplemented by written or oral questioning. Prior to the measurement, the left hemisphere (C3) and right hemisphere (C4) were tested. This initial training diagnosis the brain activity of both hemispheres. Accordingly, the hemisphere training ratio is determined. The therapeutic session took approximately 40 minutes and was done twice a week.

Measurement of behavior was observed. The frequency values given are in microvolts. The total column is not the sum of the values, but represents the average value of the achieved points after the training. This value should gradually decrease. Measurements were performed as shown in Table 2. and Table 3. Therapy for user 1 occurred at a ratio of 1: 1. During the training C3, the Beta and Theta values were monitored.

During training C4, the values of SMR and Theta were monitored. From the above table, we see that the left and right hemispheres have improved. After training, the person improved short-term memory and improved concentration.

\begin{tabular}{|c|c|c|c|c|c|c|}
\hline \multicolumn{7}{|c|}{ User 2 } \\
\hline \multirow{3}{*}{ Hemisphere } & $\begin{array}{c}\text { The name of } \\
\text { the wave }\end{array}$ & $\begin{array}{c}\mathbf{1 .} \\
\text { session }\end{array}$ & $\begin{array}{c}\mathbf{5 .} \\
\text { session }\end{array}$ & $\begin{array}{c}\mathbf{1 0 .} \\
\text { session }\end{array}$ & $\begin{array}{c}\mathbf{1 5 .} \\
\text { session }\end{array}$ & $\begin{array}{c}\mathbf{2 0 .} \\
\text { session }\end{array}$ \\
\hline \multirow{4}{*}{ Left C3 } & Delta & 30,3 & 31,8 & 29,6 & 28,8 & 32,4 \\
\cline { 2 - 7 } & Theta & 27,5 & 27,2 & 26,4 & 23,8 & 25,8 \\
\cline { 2 - 7 } & Alpha & 11,4 & 10,5 & 12,8 & 14,2 & 16,6 \\
\cline { 2 - 7 } & SMR & 7,87 & 7,65 & 8,52 & 7,76 & 8,47 \\
\cline { 2 - 7 } & Beta 1 & 7,24 & 7,61 & 7,45 & 8,24 & 9,35 \\
\cline { 2 - 7 } & Beta 2 & 8,4 & 8,95 & 9,12 & 10,3 & 11,1 \\
\hline \multirow{4}{*}{ Total } & & $\mathbf{3 , 7 8}$ & $\mathbf{3 , 6 5}$ & $\mathbf{3 , 2 6}$ & $\mathbf{3 , 1 7}$ & $\mathbf{2 , 9 4}$ \\
\hline & Delta & 30,5 & 28,9 & 28,6 & 30,2 & 30 \\
\cline { 2 - 7 } & Theta & 27,6 & 24,1 & 24,4 & 25,8 & 26,5 \\
\cline { 2 - 7 } & Alpha & 11,5 & 12,2 & 14,3 & 11,7 & 12,4 \\
\cline { 2 - 7 } & SMR & 8,68 & 7,52 & 8,12 & 9,02 & zár..35 \\
\cline { 2 - 7 } & Beta 1 & 7,92 & 7,71 & 7,77 & 7,84 & 8 \\
\cline { 2 - 7 } & Beta 2 & 9,45 & 10,33 & 9,62 & 9,95 & 9,68 \\
\hline \multirow{4}{*}{ Total } & & $\mathbf{3 , 2 1}$ & $\mathbf{3 , 1 8}$ & $\mathbf{3 , 0 8}$ & $\mathbf{3 , 0 2}$ & $\mathbf{2 , 8 6}$ \\
\hline
\end{tabular}

Table 3. Therapeutic measurement of the user 2 with EEG biofeedback

As with user 1, measurements and examinations were conducted by user 2. Self-confidence, self-confidence, and pronunciation improved. The overall course of brain waves of both hemispheres was stabilized. The aim was to verify the effectiveness and possibility of using EEG biofeedback as assistive technology for persons with learning disabilities. Through therapy, efforts have been made to harmonize brain activity.

The desired the reduction was achieved slow, "fatigue" waves of Theta and fast, "stress" Beta 2 waves, making it possible assume reduction in attenuation states, increase attention and reduce tension. About the changes in brain activity toward greater maturity reflect mainly the decrease in the ratio of slow and fast waves on the left hemisphere (theta/beta1) and right hemisphere (theta/SMR). This pre-research has shown the effectiveness of EEG biofeedback in the specified area of interest.

\section{Conclusion}

The primary objective of the pre-research was to determine whether EEG biofeedback can positively affect learning disabilities within the framework of assistive technologies. The course of therapy sessions in the course of the 20 measured session found these options. The presented results show that the desired goal has been achieved.

Learning disorders can significantly affect the life of the people and therefore it is necessary to get this issue more attention. This pre-research has shown that this method is real and effective. For further research, measurements will need to be done on a larger group of people with different learning disabilities. In addition to the group mentioned above, it will be necessary to compare the results with the control group.

We must not forget that the results are based on the individual's individual possibilities. Such measurements do not usually count with other variables such as sleep, hunger, thirst and etc. Further developments in this area will show the potential of this therapeutic method.

\section{Acknowledgments}

This paper was prepared with the support by grant no. IGA/FAI/2018/017 from Internal Grant Agency of Tomas Bata University in Zlin. 


\section{References}

[1] What is assistive technology? [online]. USA: Assistive Technology Industry Association (ATIA) [cit. 2018-09-21]. Available from: https://www.atia.org/at-resources/what-is-at/

[2] Assistive Technology [online]. TechTerms [cit. 2018-09-18]. Available from: https://techterms.com/definition/assistive_technology

[3] Tyl, J., Ptáček, R., Tylová, V. (2003). Light brain dysfunction. New methods axles. 3rd edition Prague: Biofeedback Institute

[4] What is EEG Biofeedback? [online]. Practice in Clinical and Health Psychology [cit. 2018-09-20]. Available from: http://www.drmueller-healthpsychology.com/What_is_EEG_biofeedback.html

[5] Linden, Michael \& Habib, Thomas \& Radojevic, Vesna. (1996). A controlled study of the effects of EEG biofeedback on cognition and behavior of children with attention deficit disorder and learning disabilities. Applied Psychophysiology and Biofeedback. 21. 35-49. 10.1007/BF02214148.

[6] Mosanezhad Jeddi, E., \& Nazari, M. A. (2013). Effectiveness of EEG-Biofeedback on Attentiveness, Working Memory and Quantitative Electroencephalography on Reading Disorder. Iranian Journal of Psychiatry and Behavioral Sciences, 7(2), 35-43.

[7] Enriquez-Geppert, S., Huster, R. J., \& Herrmann, C. S. (2017). EEG-Neurofeedback as a Tool to Modulate Cognition and Behavior: A Review Tutorial. Frontiers in Human Neuroscience, $11,51$. http://doi.org/10.3389/fnhum.2017.00051

[8] Shudayfat, Eman \& Moldoveanu, Florica \& Moldoveanu, Alin. (2012). A 3D Virtual Learning Environment for Teaching Chemistry in High School. 23rd DAAAM International Symposium on Intelligent Manufacturing and Automation 2012. 1.

[9] Operationalizing the NJCLD Definition of Learning Disabilities for Ongoing Assessment in School [online]. National Joint Committee on Learning Disabilities [cit. 2018-09-20]. Available from: http://www.ldonline.org/article/Operationalizing_the_NJCLD_Definition_of_Learning_Disabilities_for_Ongoing_ Assessment_in_School

[10] Types of Learning Disabilities [online]. US: Learning Disabilities Association of America [cit. 2018-09-22]. Available from: https://ldaamerica.org/types-of-learning-disabilities/

[11] Dvořák, K., Pán, L. (2008). Communication and thinking. České Budějovice: College European and regional studies.

[12] Neurofeedback [online]. Prague: Therapy centre [cit. 2018-09-22]. Available from: http://www.therapycentre.eu/neurofeedback/

[13] Your 5 Brainwaves: Delta, Theta, Alpha, Beta and Gamma [online]. Lucid [cit. 2018-09-23]. Available from: https://lucid.me/blog/5-brainwaves-delta-theta-alpha-beta-gamma/

[14] Electrical activity of the brain [online]. Prague: Therapy centre [cit. 2018-09-23]. Available from: http://www.therapy-centre.eu/elektricka-aktivita-mozku/ 